\title{
Necessary Conditions and Situational Variables of Payments for Ecosystem Services
}

\author{
Pingan Xiang1,2*, Weiqi Xiang ${ }^{3}$, Yu Lu ${ }^{1}$ \\ ${ }^{1}$ School of Business, Hunan Agricultural University, Changsha, China \\ ${ }^{2}$ Key Laboratory of Rural Ecosystem Health in Dongting Lake Area of Hunan Province, Hunan Agricultural University, Changsha, \\ China \\ ${ }^{3}$ Canvard College, Beijing Technology and Business University, Beijing, China \\ Email: *xiangpa@hunau.edu.cn
}

How to cite this paper: Xiang, P.A., Xiang, W.Q. and Lu, Y. (2021) Necessary Conditions and Situational Variables of Payments for Ecosystem Services. Open Journal of Ecology, 11, 1-23.

https://doi.org/10.4236/oje.2021.111001

Received: November 11, 2020

Accepted: January 1, 2021

Published: January 4, 2021

Copyright $\odot 2021$ by author(s) and Scientific Research Publishing Inc. This work is licensed under the Creative Commons Attribution International License (CC BY 4.0).

http://creativecommons.org/licenses/by/4.0/

\begin{abstract}
Clarifying the necessary conditions for the emergence of payments for ecosystem services (PES) and the situational variables that affect PES is the basis for their interpretation, prediction, and selection. This article proposes an analytical framework for the emergence of PES and argues that the key to determining whether PES can occur and whether a selected PES program is appropriate is to evaluate the net gain. When payers anticipate that a PES program will provide a satisfactory number of ES and a net gain over the opportunity cost and will cover all costs, it is assumed that the program will be implemented. When it is difficult to accurately evaluate the net gain of PES, the situational variables that affect the costs and benefits need to be examined. The group characteristics, ES characteristics, spatial and temporal contacts between the suppliers and demanders, correlation with private goods and additionality are important situational variables that affect the emergence and choice of PES.
\end{abstract}

\section{Keywords}

Payments for Ecosystem Services, Necessary Conditions, Situational Variable, Decision Making

\section{Introduction}

Ecosystem services (ES) are the fund-service resources that human beings acquire from the ecosystem, some of which are irreplaceable [1] [2]. Changes in ES have serious impacts on human well-being [2] [3] [4]. Many ES are non-exclusive in use, and some are noncompetitive and thus ignored by the market [1] [5]; 
thus, decision makers rarely take into account their importance [6]. Since the second half of the 20th century, the global ecosystem has been degrading rapidly due to the rapid world population and economic growth and the excessive human demand for ecosystem services, and most ES are becoming scarce [1] [3]. Reasonable ecosystem management measures can often reverse the degradation of ES [2]. Payment for ecosystem services (PES) is an institutional arrangement that provides ES suppliers with positive financial incentives [7] [8] [9] [10]. PES schemes are attracting more and more attention from scholars and conservationists [11]. PES has been introduced in many countries and regions [12] and has become a common practice to address the degradation of ES [10] [13]. However, PES remains multi-facetted with many diverse definitions [14], and two main conflicting viewpoints exist.

One view is that efficiency is a priority. This view argues that PES should put the Coase theorem into practice. Wunder (2005) defines PES as: "a voluntary transaction where a well-defined service (or a land use likely to secure that service) is being 'bought' by a (minimum one) ES buyer from a (minimum one) ES provider if and only if the ES provider secures ES provision (conditionality)" [7]. This definition defines ES in a narrow sense. Scholars ascribing to this view believe that those with the most adequate information about the value of ES can directly participate in the process, ensure that the PES mechanism runs well with a clear motivation, can directly observe whether services are supplied efficiently and (if necessary) can renew or terminate the agreement [15]. Thus, voluntary direct market agreements between ES users and suppliers can achieve optimal allocation of resources. People with this view see PES as a mechanism based on markets or similar mechanisms and favor direct beneficiaries (users) paying for ES supply activities [7] [16]. PES payers and decision makers are actual users, and ES are a fully voluntary transaction. PES can be categorized as Coasean PES, private PES or user-financed PES label [10]. Although many supporters of this view agree with some functions of government intervention, most emphasize only the role of government in defining property rights, forming executive contracts and reducing transaction costs [1]. However, many ES have non-exclusive features in occupancy [1], which means that the voluntary improvement of ecosystem management is a positive externality. Without government intervention, the ES supply will be inadequate [8] [17]. Moreover, the adoption of a market approach may lead to very unequal distribution, and obtaining sufficient payment capacity may require involuntary measures such as taxation or non-voluntary means of mandatory fees [1]. In this view, PES is thus a government-financed mechanism, as Muradian et al. (2010) defined PES: "A transfer of resources between social actors, which aims to create incentives to align individual and/or collective land use decisions with the social interest in the management of natural resources" [8]. This definition is referred to as broad PES and emphasizes the multiple objectives of the sustainability of ecosystems, a scenario in which fair distribution takes precedence over efficiency [1] [18], and the non-excludability of government payments [8]. Many PES programs that have been implemented 
involve government intervention and public payment schemes [15], such as $\mathrm{Pa}$ gos por Servicios Ambientales (PSA) in Costa Rica, Pagos por Servicios Ambientales Hydrológicos (PSA-H) in Mexico, and the Natural Forest Conservation Program (NFCP) and Sloping Land Conversion Program (SLCP) in China [14]. Government-financed PES is similar to environmental subsidies, the payments are derived from special charges and taxes, which are usually marked as Pigouvian PES [17] [19]. The payer in government-financed PES is not the user, and the government has the right to make a payment decision. This arrangement at least has a certain degree of compulsion in payment.

In addition to government-financed PES and user-financed PES, joint userand government-paid PES programs [10] [14] [20] [21], non-government organization (NGO)-paid PES programs [22] [23] [24], and joint non-user, userand government-financed PES programs [25] [26] exist. Most of the existing PES programs are hybrids of Coasean PES and Pigouvian PES [10]. Although the definition of PES provided by Wunder ${ }^{1}$ (2015) has largely filled the gap ${ }^{2}$ between narrow PES and the broad PES [27], PES can be defined only in terms of the characteristics of the program, and such a definition does not automatically provide an explanation for the emergence PES. The previous literature lacks discussions on this area, and an analysis framework is needed to provide a basis for the interpretation, prediction and selection of PES. This is the purpose of this article.

The basic point of this paper is that PES types fall along a spectrum ranging from user-financed PES to government-financed PES. The driver behind PES is that the payer expects to obtain the maximum net income, and an explanation of PES emergence should start with an evaluation of costs and benefits. However, in reality, it is not always possible to accurately evaluate PES costs and benefits. In this case, it is necessary to investigate the situational variables that affect the emergence of PES.

In the second part of this paper, we will analyze the necessary conditions for the emergence of PES. In the third part, the cost and income composition of different types of PES are analyzed, and an investment model is used to describe them. In the fourth part, the situational variables that affect the emergence of PES are analyzed. The fifth part is the conclusion

\section{The Necessary Conditions for PES Emerging}

A new institutional arrangement will occur only in two cases, namely, one in which the new arrangement changes the potential income and another in which

${ }^{1}$ Wunder (2015) redefined PES as voluntary transactions between service users and service providers that are conditional on agreed rules of natural resource management for generating offsite services.

${ }^{2}$ The new definition no longer sticks to the full voluntariness of the agreement between suppliers and demanders, replacing "ES provision" with "agreed rules of natural resource management", replacing "buyer" with "service users", and replacing "seller" with "service providers." Payments provided through organizations cannot be ruled out. ES need not be well-defined, but we need stick to "generating offsite services," where ES beneficiaries are external to the physical site where the ES is generated. 
the costs of that innovation will make such an arrangement modification worthwhile [28]. We assume that PES occurs because some private individuals or organizations expect to bear the costs of ES supply and hope to achieve some of the benefits that would not be possible under the old system. We can view all people who benefit from a PES program as a group and assume that every beneficiary (user) is rational and that the motivation of the users is to maximize benefits. All members of the beneficiary group have a common interest in obtaining benefits from the PES program, but they may have no shared interest in taking the cost. When an individual (a person, an enterprise or an NGO) is supplied with ES, they will not be excluded from the benefits, so they may not have the incentive to bear the cost for ES that the group incurs voluntarily. $V_{t}, V_{i}$ and $V_{c}$ are used to represent the values of the beneficiary group, the individual and the sub-groups formed by the individual in the group, respectively, derived from the PES program. Generally, the gains of a group are always greater than those of the individual or the sub-group, that is, $V_{t}>V_{i}$ and $V_{t}>V_{c}$. The total value that the beneficiary group obtains from a PES program depends on the size of the group $\left(S_{g}\right)$ and the quantity of ES obtained $(Q)$, that is, $V_{t}=S_{g} Q$. The size of the beneficiary group depends not only on the number of individuals in the group but also on the value of the target ES to each individual in the group. The benefit of an individual member depends on his portion of the total gain of the group $\left(P_{i}\right)$; $P_{i}=V_{i} / V_{t}$. The individual's share of the total gain of the group depends on the number of individuals in the group and how much he can benefit from the target compared to other individuals. The net gain $\left(N V_{i}\right)$ generated by any individual gain for any number of ES $(Q)$ is equal to the gain of an individual $\left(V_{i}\right)$ minus the cost $(C), N V_{i}=V_{i}-C$. Thus, we should consider the individual payment for different quantities of ES gains or losses. This payment depends on the way that the net gain of the individual varies with the number of ES $(Q)$, that is, $\frac{\mathrm{d} N V_{i}}{\mathrm{~d} Q}=\frac{\mathrm{d} V_{i}}{\mathrm{~d} Q}-\frac{\mathrm{d} C}{\mathrm{~d} Q}$. When the gain of an individual is maximized, $\frac{\mathrm{d} N V_{i}}{\mathrm{~d} Q}=0$. Because $V_{i}=P_{i} S_{g} Q, P_{i}$ and $S_{g}$ are constant, $\frac{\mathrm{d} P_{i} S_{g} Q}{\mathrm{~d} Q}-\frac{\mathrm{d} C}{\mathrm{~d} Q}=0$ and $P_{i} S_{g}-\frac{\mathrm{d} C}{\mathrm{~d} Q}=0$. This relation shows the quantity of ES that are paying for their own costs. Because $\frac{\mathrm{d} V_{i}}{\mathrm{~d} Q}=P_{i} \frac{\mathrm{d} V_{t}}{\mathrm{~d} Q}, P_{i} \frac{\mathrm{d} V_{t}}{\mathrm{~d} Q}=\frac{\mathrm{d} C}{\mathrm{~d} Q}$. This relation means that the quantity of ES is optimal when the product of the ratio of individual gain to group gain and the rate of the group gain equals the rate of increase in the total cost of ES supply. Whether the individual will spontaneously pay for ES is the most important factor. Clearly, when an individual acting independently reaches optimal gain, if $P_{i}>\frac{C}{V_{t}}$, he might provide ES, because if $P_{i}>\frac{C}{V_{t}}$, i.e. $\frac{V_{i}}{V_{t}}>\frac{C}{V_{t}}$ or $\frac{V_{t}}{C}>\frac{V_{t}}{V_{i}}$, then $V_{i}>C$. In this way, the individual's benefit will exceed the cost, that is, $V_{i}>C$.

To determine whether an individual in a group will volunteer to pay for ES, two features need to be identified. First, we need to define the optimal number 
of ES that an individual demands, which is given by $P_{i} \frac{\mathrm{d} V_{t}}{\mathrm{~d} Q}=\frac{\mathrm{d} C}{\mathrm{~d} Q}$. Second, it is necessary to determine whether the gain of a payer exceeds the supply cost when reaching the optimal ES number, that is, whether $V_{i}>C \quad\left(\right.$ or $\left.P_{i}>\frac{C}{V_{t}}\right)$. In brief, when an individual's gain exceeds the cost of providing ES for a group, then an individual can be considered to provide ES. It seems that the user will not pay a voluntary fee unless a small number of users receive a large proportion of the proceeds [10], but this dynamic is not a necessary condition for the emergence of user-financed PES. Figure 1 shows that as long as the scope of the number of ES $(Q)$ that an individual need is $Q_{a} \leq Q \leq Q_{b}$, he will have net revenue. Even if the number of ES for an individual is not optimal, $P_{i}$ will also exceed $C / V_{t}$ because $V_{i}>C^{3}$. However, even if the PES program meets the number of ES required by the individual and satisfies the condition $V_{i}>C$, the individual is not guaranteed to be able to implement the program spontaneously unless the cost does not exceed the budget when the individual receives a net gain, that is, he has enough capacity to pay the cost, and the net revenue he gains from investing resources into the PES program exceeds the opportunity cost of the net revenue from investing resources into alternative activities, that is $N V_{i}>C_{o}\left(C_{o}\right.$ denotes the opportunity cost). Otherwise, the individual will not carry out PES.

It seems that if an individual has the ability to pay all the cost of implementing the PES program alone, if he can achieve a net gain, and if the net gain is higher than the opportunity cost, an individual-financed PES can be assumed to occur voluntarily and will not be affected by free riding. For example, the honeybee pollination ES is beneficial to increasing the production of orchards. An orchardist does not expect that the bees spreading pollen will also benefit the nearby orchards without additional payment for ES, but as long as the income is greater than the payment, he would still have the motivation to pay for the pollution ES.

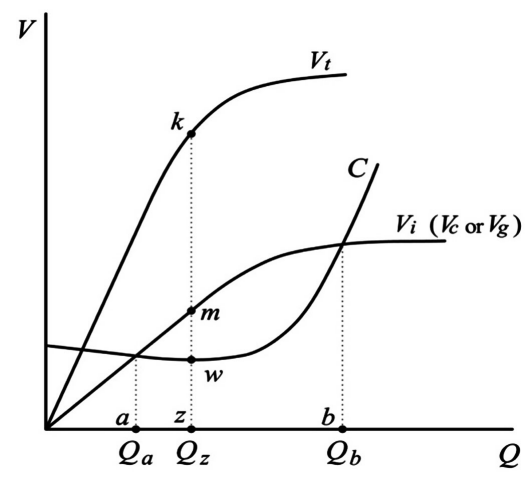

Figure 1. The conditions for the emergence of PES.

${ }^{3}$ When the number of ES is $Q_{z}$, the supply cost is $C_{(z)}=w z$, the group revenue is $V_{t(z)}=k z$, and the portion of revenue payers to group is $P_{i}=\frac{m z}{k z}$, the individual revenue $(m z)$ exceeds the supply cost (wz). So, $\frac{m z}{k z}>\frac{w z}{k z}$, that is, $P_{i}>\frac{C(z)}{V t(z)}$. 
When individual payments are unprofitable or the individual is unable to bear the cost, the group members need to cooperate to implement PES. Sometimes, the cost of establishing an organization makes the first ES relatively expensive. The beneficiary group will also find that when the demand exceeds a certain degree, the difficulty and increased cost of extracting the next marginal ES will increase disproportionately, and the average cost curve is $U$ shaped. If the cooperative group can determine the number of ES supplied (given by $P_{c} \frac{\mathrm{d} V_{t}}{\mathrm{~d} Q}=\frac{\mathrm{d} C}{\mathrm{~d} Q}$, where $P_{c}$ denotes the portion of the share of the total group gain that the cooperative sub-group obtains) and agree to pay for it, not only does the gain of the cooperative sub-group exceed the total supply cost but each partner's gain also exceeds the cost of the burden, that is, $V_{c}>C$ and $V_{i}>C_{i}\left(C_{i}\right.$ is the cost the individual in a cooperative sub-group bear). A cooperator-financed PES can be assumed to occur. Similar to individual-financed PES, as long as the scope of the number of ES $(Q)$ cooperator-financed PES provided is $Q_{a} \leq Q \leq Q_{b}$, partners will acquire a net gain (Figure 1).

When the conditions for spontaneously generating individual-financed PES or cooperator-financed PES are not satisfied and the beneficiary group strongly calls for increasing the supply of ES, if the government has the ability to pay and the expected net gain of the PES exceeds the opportunity cost (that is $V_{g}>C$ and $N V_{g}>C_{o}$ ), as long as the scope of the number of ES supplied is $Q_{a} \leq Q \leq Q_{b}$, PES will be implemented.

\section{Variables Affecting the Assessment of Net Gains from PES}

In the previous section, we proposed that the condition for the emergence of PES is that the net gain of a payer is more than the opportunity cost. How much the expected net gain obtained from PES is a key factor affecting the potential payer's selection of the PES type. In this section, we discuss the explanatory variables that affect the assessment of net gains from PES. Evaluating the expected net gain from PES not only begins with a cost comparison but also depends on an earnings comparison [29]. Regardless of the kind of PES, there will be ES production costs and transaction costs. The cost composition of different payment arrangements is different [1] [30] [31]. However, regardless of the kind of arrangement, there will be contractual costs between payers and producers, including information collection costs, bargaining costs, monitoring costs and contract execution costs, and payers eventually should bear all of these costs. Cooperative payment arrangements may also result costs for establishing, maintaining, executing and regulating contracts as well as organization costs due to the organizations and contracts among payers. A government-financed PES or a cooperative payment arrangement with the government may also result in sunk costs due to undesired government decisions [28] because regardless of whether participants are satisfied with the decision, the participants may be still be influenced by such a decision. 
We see the suppliers' benefit from PES as the cost of different payment arrangements, the gain generated by PES can be divided into two categories: the payer's gain and the free rider's gain. The target ES that payers obtain can be for production or for consumption. We can define the utility for the consumption of ES and the revenue obtained from production as income, and the value payers obtain can be defined as a value to them $\left(V_{p}\right)$. In general, there is free riding in ES use. Different payers have different evaluations of the benefits of free riders [32]. When the payer is an NGO or a government devoted to public welfare, these entities are the agents of the direct beneficiaries, and the beneficiaries receive the income regardless. Therefore, the incomes of free riders overlap with those of the payers.

We also need to realize that the benefits and costs of PES may not disposable [33] [34] and can usually be measured annually. We can consider all kinds of costs as investments, and we can further analyze these investments by establishing an investment model. Considering that cost and income will occur over time, the present value of these flows may also be discounted due to future devaluation. Then, we should consider discounting evaluations of income and cost. The appropriate discount rate is the interest rate for payers who can borrow money or the desired rate when they have limited resources to invest. A higher discount rate means that it is less important to protect resources in the future. If a payer knows the internal rate of return on an investment, then he can compare the internal rates of return of different programs and easily determine which programs are more profitable. If the internal rate of return of one program exceeds that of other programs, this program can get a higher net present value since the net profit $(N V)$, income $(V)$ and cost $(C)$ of PES can be regarded as the net income value $(N P V)$, income present value $(N V)$ and cost present value $(P C)$. To maintain consistency, this article uses $N V, V$ and $C$ to replace $N P V, P V$ and $P C$, respectively. $N P V=P V-P C$ can be written as $N V=V-C$, and thus,

$$
\begin{gathered}
V=\frac{\left(V_{d 1}+V_{f 1}\right)}{1+r}+\frac{\left(V_{d 2}+V_{f 2}\right)}{(1+r)^{2}}+\cdots+\frac{\left(V_{d n}+V_{f n}\right)}{(1+r)^{n}} \\
C=\frac{\left(C_{p 1}+C_{t b}\right)}{1+r}+\frac{\left(C_{p 2}+C_{t b}+C_{s}\right)}{(1+r)^{2}}+\cdots+\frac{\left(C_{p n}+C_{t b}+C_{s}\right)}{(1+r)^{n}}+C_{t p}
\end{gathered}
$$

In (1), $V_{d}$ denotes the direct income that payers expect to get from PES; that is, the utility ${ }^{4}$ from increasing ES consumption that payers expect to get and the income from increased ES as production factors. $V_{f}$ denotes the expected free rider's income from the increase in ES, and the subscripts $1,2, \cdots, n$ denote the year. $r$ denotes an appropriate discount rate for payers. In (2), $C_{p}$ denotes what payers expect to pay to the ES providers in a certain year, that is, the ES production cost. $C_{t b}$ denotes the expected transaction cost between providers and ${ }^{4}$ Assuming that there is a reliable and effective method to convert utility to income. For example, to convert the utility derived from the consumption of the water service provided by forest ecosystems to the beneficiaries into revenue, which can be expressed by the equivalent cost of purchase water in the market. 
payers, and $C_{s}$ indicates the sunk cost ${ }^{5}$ caused by undesirable government decisions (the cost of a disadvantageous decision ${ }^{6}$ times the probability of its emergence). Because these costs are spread over the life of the organization, the costs need to be discounted. $C_{t p}$ is the transaction cost that payers expect to occur among them, and the cost must be borne now so it is not subject to any discount [28].

The incomes and costs are what the payers are expecting to happen, and the expected value is the product of the estimated value of the earnings or costs that can be realized with probability $P$ [28]. Therefore, the benefit item in (1) should actually be $\left(V_{d n}+V_{f n}\right) P_{b}$, where $P_{b}$ is the probability of the emergence of $\left(V_{d n}+V_{f n}\right)$. The cost item in (2) should be $\left(C_{p n}+C_{t b}+C_{s}\right) P$, where $P_{c}$ is the probability of the emergence of $\left(C_{p n}+C_{t b}+C_{s}\right)$. These probabilities vary depending on the type of PES because the net present value of a particular PES may vary depending on the estimated cost or the probability of implementation. Because these features are complex to express, these additions are not included in this paper.

In an individual-financed PES, voluntary transactions are carried out in full accordance with market rules, and there is neither a transaction cost nor the cost of compulsory transaction. However, there will be a cost to collect information on the ES supply and transaction costs arising from the negotiating, drafting, executing and regulating contracts between demanders and suppliers ${ }^{7}$. This arrangement of ES users is not limited to payers and perhaps even free riders. For example, when the water source for a certain distillery has been polluted by upstream agricultural production activities, to ensure the clean water supply, a PES agreement is reached between the distillery and the farmers who pollute the water source that encourages the farmers to abandon the polluting activities. If clean water is not for exclusively use, other water users will become free riders and benefit from the PES program. Then, in an individual-financed PES, there is no requirement to pay the expenses of the organization, nor are there organization costs arising from the cooperation among payers or externally imposed sunk costs. Thus, only the need to consider the operation and the transaction costs between payers and providers. Free riders using part of the ES from the PES may affect payer's incomes. Payers may receive indirect incomes derived from the positive evaluation of free riders ${ }^{8}$. This income can be expressed as the weight $\left(w_{i}\right)$, the payer's evaluation of 1 unit of income to free riders, equivalent to how much he gets, multiplied by the income of free riders. $i$ denotes the indi-

\footnotetext{
${ }^{5} \mathrm{~A}$ cooperative payment with the government may have a negative impact on the other participants because of the government's power of compulsion.

${ }^{6}$ The cost of adverse decision making can be expressed by the income gap between consensual government decisions and compulsory government decisions.

${ }^{7}$ For the sake of convenience, the transaction cost is divided into three parts: the transaction cost between payers and providers, transaction cost among (potential) payers and compulsory cost.

${ }^{8}$ This article assumes that payers have no negative assessments of free riders. Because it is impossible or difficult to establish exclusive property rights for free riders, this cannot be blamed on the free riders, and payers regard paying the free riders as improving the well-being of others, which also improves their utility.
} 
vidual-financed PES, and the net present value of income in such a PES scheme can be expressed as:

$$
\begin{aligned}
N V_{i}= & \left(V_{d 1}^{i}+w_{i} V_{f 1}^{i}-C_{p 1}^{i}-C_{t b 1}^{i}\right) /(1+r) \\
& +\left(V_{d 2}^{i}+w_{i} V_{f 2}^{i}-C_{p 2}^{i}-C_{t b 2}^{i}\right) /(1+r)^{2} \\
& +\cdots+\left(V_{d n}^{i}+w_{i} V_{f n}^{i}-C_{p n}^{i}-C_{t b n}^{i}\right) /(1+r)^{n}
\end{aligned}
$$

Unlike individual-financed PES, user cooperative-financed PES is a collective payment arrangement. There will be organization costs (including contractual costs) among individuals agreeing to pay these costs, negotiation costs between payers and potential payers, and transaction costs between producers and payers. We classify the organization costs among payers and the negotiation costs between payers and potential payers as transaction costs $\left(C_{t p}\right)$. In PES, not only does the payer get gain but the free riders may also gain part of the benefit. Generally, the cooperative payers' evaluation of free riders' enjoyment is significantly lower than that of themselves, but the weight they give may be higher than that if the payer is an individual user. Using $c$ to denote a voluntary cooperation payment arrangement, we use $N V_{c i}$ and $w_{c i}$ to denote the net income of the individual payer and the weight of the individual payer's assessment of free riders, respectively, in a voluntary cooperation payment arrangement. The net present value of the individual income for this arrangement is as follows:

$$
\begin{aligned}
N V_{c i}= & \left(V_{d 1}^{c}+w_{c i} V_{f 1}^{c}-C_{p 1}^{c}-C_{t b 1}^{c}\right) /(1+r) \\
& +\left(V_{d 2}^{c}+w_{c i} V_{f 2}^{c}-C_{p 2}^{c}-C_{t b 2}^{c}\right) /(1+r)^{2} \\
& +\cdots+\left(V_{d n}^{c}+w_{c i} V_{f n}^{c}-C_{p n}^{c}-C_{t b n}^{c}\right) /(1+r)^{n}-C_{t p}^{c}
\end{aligned}
$$

The total net income of each payer is the sum of the net income of such a PES, that is, $N V_{c}=\sum N V_{c i}(i=1,2, \cdots, n)$.

Compared with voluntary cooperator-financed PES, a government-financed PES or government participation-financed PES can reduce many transaction costs, especially the transaction costs of collective decisions [35]. However, such programs have endogenous additional mandatory costs; that is, every participant is subject to the compulsive force of the government. Regardless of whether the participant is satisfied with the arrangement, he has no freedom to quit. However, the government's mandatory arrangements could generate a high profit because the government can use its power to achieve a solution that no voluntary negotiation can achieve [28]. In comparison with other PES schemes, if the ES supplier is under the jurisdiction of a paid government, the cost of the agreement between a payer and a producer incurred by the government (participating or cooperating) may be low as the government may exercise its coercive force. $N V_{c g i}$ and $w_{c g i}$ are used to denote the net income and the weight of the evaluation of free riders of the individual payer in a government cooperative payment PES. The present value of net income of each payer in this type PES is expressed as: 


$$
\begin{aligned}
N V_{c g i}= & \left(V_{d 1}^{c g}+w_{c g i} V_{f 1}^{c g}-C_{p 1}^{c g}-C_{t b 1}^{c g}-C_{s}^{c g}\right) /(1+r) \\
& +\left(V_{d 2}^{c g}+w_{c g i} V_{f 2}^{c g}-C_{p 2}^{c g}-C_{t b 2}^{c g}-C_{s}^{c g}\right) /(1+r)^{2} \\
& +\cdots+\left(V_{d n}^{c g}+w_{c g i} V_{f n}^{c g}-C_{p n}^{c g}-C_{t b n}^{c g}-C_{s}^{c g}\right) /(1+r)^{n}-C_{t p}^{c g}
\end{aligned}
$$

The central government or the local government pays the PES alone, and no organization costs will be generated because no cooperation is needed. Using $g$ to represent this payment arrangement, the net income present value of this arrangement is as follows:

$$
\begin{aligned}
N V_{g}= & \left(V_{d 1}^{g}+w_{g} V_{f 1}^{g}-C_{p 1}^{g}\right) /(1+r)+\left(V_{d 2}^{g}+w_{g} V_{f 2}^{g}-C_{p 2}^{g}\right) /(1+r)^{2} \\
& +\cdots+\left(V_{d n}^{g}+w_{g} V_{f n}^{g}-C_{p n}^{g}\right) /(1+r)^{n}
\end{aligned}
$$

Organization costs will be generated in the intergovernmental cooperation payment PES. The share of this cost may be low and will be negligible, especially due to the intergovernmental cooperation among adjacent local governments in one country. However, in the cooperation between the superior and subordinate governments, the decision of the superior government may impose sunk costs on the lower level partners. $N V_{c g}$ is used to denote the net income of the each government in a government cooperative payment PES. The present value of net income of each payer in this type PES is expressed as:

$$
\begin{aligned}
N V_{c g}= & \left(V_{d 1}^{c g}+w_{g} V_{f 1}^{c g}-C_{p 1}^{c g}-C_{t b 1}^{c g}-C_{s}^{c g}\right) /(1+r) \\
& +\left(V_{d 2}^{c g}+w_{g} V_{f 2}^{c g}-C_{p 2}^{c g}-C_{t b 2}^{c g}-C_{s}^{c g}\right) /(1+r)^{2} \\
& +\cdots+\left(V_{d n}^{c g}+w_{g} V_{f n}^{c g}-C_{p n}^{c g}-C_{t b n}^{c g}-C_{s}^{c g}\right) /(1+r)^{n}
\end{aligned}
$$

Although this article provides only a simple net present value expression, this expression provides us with some valuable information. 1) The PES with greater potential net incomes is more likely to be preferred by payers, but unless the largest net income of the PES is higher than its opportunity cost, the PES will not be put into practice. 2) The higher the discount rate is, the smaller the net present value the payer is expected to receive, which could hinder the incentive to pay for ES. When a payer is a user and especially a manufacturing enterprise, the discount rate is likely to be higher than that for NGOs and/or governments. The longer the cost or benefit occurs, the more the users will discount the present value. 3) In providing the same number of ES, different numbers of free riders may affect the choice of different PES schemes. In general, the payers' assessment of free riders is less than that of their own enjoyment, which may partly explain why single user-financed PES and user cooperative-financed PES schemes are rare in the case of large numbers of free riders. 4) The transaction cost between ES supply and demand affects the maximization of net income. In ensuring the realization of cooperation objectives, the more resources that are invested, the more the transaction revenue will be diluted. The transaction cost generated may be higher than the benefits that both sides get from the scheme [36]. 5) A cooperator-financed PES will generate organizational costs due to the cooperation of the payer. Such costs cannot be delayed. If this cost ac- 
counts for a large proportion of the total initial cost, or if the alternative use of the cost can produce higher returns (or higher interest rates), the possibility that PES will occur will be affected because the cooperative arrangement will often depend on the participants' bargaining process. At the initial stage of development, when the organization costs or interest rates are higher, a government payment arrangement may be appropriate because this arrangement has no organization costs or the costs are quite low. 6) If ES payers and producers are all governments, negotiations to reach an agreement may not be necessary, or the cost of coordination may be low, in which case, the transaction cost may be relatively small. 7) The high sunk cost may affect the form that the government (participation)-financed PES takes, especially when the beneficiaries are few.

\section{Situational Factors Affecting the Choice of PES Types}

Both cost and income are the explanatory variables that affect the decisions of potential payers. However, only when all costs and incomes can be measured through effective and reliable methods, when the relevant income and cost information can be completely and accurately converted into expected cost and income by individuals, and when a person acts in a non-strategic way [37] can the net income from PES be evaluated accurately. Unfortunately, these conditions are not always met for the analyst. Therefore, to explain or predict the emergence of PES, it is sometimes necessary to examine the situational variables that influence the evaluation of PES costs and benefits.

\subsection{The Characteristics of Groups}

Sometimes, individuals do not need force or any outside incentive for the implementation of PES, especially when beneficiary groups and supplier groups are small. Each member of the beneficiary groups, or at least one of the members, will find that his personal benefits from the PES exceed the total cost even if he bears all costs and benefits more often than not in the implementation of PES. For example, in the 1980s, the water quality of the Rhin-Meuse basin in northeastern France is polluted by agricultural activities, and the French Vittel Perrier bottled water company, which uses the water from this river basin to produce natural mineral water, must make a choice between protecting water and building a water filtration plant. Vittel realized that protecting the water supply was more cost-effective than setting up water quality filters and reached a PES agreement covering more than 10,000 hectares with 40 farms [38]. The French National Agronomic Institute (1997) estimated that compared with the previous scenario, one hectare of well-managed farmland can save the cost of filtering approximately 3000 cubic meters of potable water per year, and thus, the PES project is efficient [38].

However, for those PES programs needing cooperation among the members of the beneficiary group to be implemented, reaching an agreement will not only generate negotiation costs but will also require incentives to organize all the members to reach an agreement. When the group size is small and information 
is clear among individuals, the cooperation cost of the individual users and the motivation for free riding may be quite low [32]. As long as the individual in the group gains enough profit, he will seek to promote universal consent, hoping to reap the benefits of a mutually agreed common interest. In addition, when supplier groups are small, the cost of transactions between payers and suppliers may not be high. For example, The Paso de Los Caballos River Basin located in the municipality of San Pedro del Norte of Nicaragua covers an area of approximately 740 hectares, and agriculture, which is mainly based on cattle and grain farming, is the main economic activity in the area, income from which accounts for $70 \%$ of the household income. However, the water quality problems caused by agricultural activities forced 125 residents in San Pedro del Norte to set up a water association and reach a PES agreement with the 5 upstream land stewards. This process involved the reforestation and conservation of 39.2 hectares of priority areas [39]. Cooperation organizations are similar to water associations, and their decision makers negotiate on behalf of all users with providers for PES. The main role of these organizations is to reduce transaction costs. With the expansion of beneficiary groups, the appearance of such organizations to reduce transaction costs is inevitable [40]. The larger the group is, the more the organization needs. However, the larger the group is, the more difficult it is to establish a cooperative organization, which may increase the organization cost. Organization cost is a monotonous increasing function of the number of individuals in a group. However, if the beneficiaries have a social preference, the cost of establishing a partnership may be low, and it is possible to establish a user co-financed PES to avoid the "prisoner's dilemma" [41]. Moreover, the payers with characteristics of social preferences ${ }^{9}$ are more likely to evaluate the free riders higher than those with characteristics of self-regarding preferences, which will increase the expected revenue of the payers.

For large groups, there is a universal dependence on all members. The behavior of all others is viewed by individuals as a whole, and individuals simply adjust their behavior according to the overall behavior of others and do not expect their actions to affect other members' behaviors [32]. The transaction cost of reaching a cooperative payment agreement among individuals may be too high for individuals to give up the effort. Therefore, when faced with a large-scale group dilemma, market transactions cannot produce the optimal results.

The argument for government providing ES with the characteristics of public goods is precisely because the market is not sufficient to reach a multilateral agreement, and government as an agent of demanders can reduce transaction costs greatly, and thus, such an approach is relatively efficient. This argument provides support for government-financed PES [16]. For example, in order to radically reduce environmental degradation and protect biodiversity, the Chinese government has been implementing the NFCP since 2000. The program involves 17 provinces and is the world's largest forest ecosystem protection pol-

${ }^{9}$ Social preferences refer to the desire to care for the well-being of others and maintain ethical norms, and self-regarding preferences refer to the concern of only one's own state [41]. 
icy, with 96.2 billion Yuan invested from 2000 to 2010 to cover the cost of, reforestation stopping deforestation and the resettlement of surplus staff in state-owned forestry enterprises. Most of the payments are paid by the central government, and a small part is paid by the local government [42]. Similarly, the $S L C P$ for reducing soil and water erosion began in 1999 and covers 25 provinces (regions and municipalities). The central government compensates farmers to convert farmland to forests and provides subsidies to farmers for planting seedlings and reforestation. The investment amounted to 103 billion RMB Yuan from 1999 to 2005 [42]. These two huge PES projects, which involve most of China's population and regions, are too expensive for an individual payment arrangement or a user cooperation payment arrangement. Moreover, it is difficult to establish a payment arrangement between the user and the government because the transaction costs of large-scale cooperation negotiation can be huge, and this process may take a long time. In this case, a government payment scheme may be the best choice. Another case is the Catskill river basin management program, which improves water quality for millions of users in New York City. In total, 90\% of the drinking water for 9 million residents is provided by the Catskill/Delaware catchment, and the rest is supplied by the Croton catchment. In 1993, the Environmental Protection Agency asked the city to invest 40 - 60 billion dollars in a filtration system to ensure that the water quality complied with federal standards. Coupled with 3 - 5 billion dollars in annual operating costs, the total present value of the cost was approximately 80 - 100 billion. Later, New York City was allowed to use an emission reduction program, which was more effective in terms of cost in reducing point source and non-point source pollution through negotiations. This program involved buying the ES that land managers in the upstream Catskill/Delaware catchment provide. New York City spent $\$ 1.5$ billion on this program, less than $20 \%$ of the budget for the filtration system. Such a program is not only beneficial to all the population of New York City but also to other downstream water users in the Catskill basin. The New York City water supply must be paid for providing more water, but the cost of the PES program is less than the filtration system. The cost of the program comes not only from New York City's tax on water users but also from New York City bonds, the federal government, the New York state government, and local governments in the valley [15] [38].

\subsection{The Characteristics of Ecosystem Services}

Exclusiveness determines whether ES can be allocated by the market, rivalness determines whether ES should be allocated. Market-based PES requires exclusive property rights on ES. When the law gives ES exclusive property rights and the beneficiaries are able to build exclusive property rights economically, market-based user-financed PES schemes can be established as long as the beneficiaries expect net income. However, pure user-financed PES schemes are rare, and most PES cases do not meet Wunder's definition for PES [1] [8] [14]. Muradian et al. (2010) said: "We think this is problematic, since a prescriptive definition of 
PES that excludes the bulk of PES cases can be deemed at least flawed" [8]. Some of the possible reasons for failing to meet the five standards of Wunder are as follows: Due to the nature of common goods from ES, a forced payment may be required to ensure that all users pay their fair share, otherwise, there may be a free rider [18]. The lack of understanding of the mechanisms behind the emergence of ES means that accessing the market with complete information is not possible [1]. The lack of awareness of ES also means that the cost of information collection may be high. High transaction costs are the main reason why the Coase theorem is difficult to realize [8] [9].

For the ES that needs to be increased, government intervention is inevitable if the conditions for a voluntary payment arrangement cannot be met. ES has a large range of exclusive changes, from fairly easy to impossible, and these changes are seriously affected by the spatial distribution of the target ES [1]. For ES with non-exclusive features, such as climate stability, the role of biodiversity in support of all services, gas regulation, protection from ultraviolet radiation and human interference regulation, open access is inevitable, and the transaction costs of market settlement are either huge [1] or unfair, especially when those who use the ecosystem directly are poorer than those use the ecosystem to provide services. Providing these non-exclusive services involves real costs, and non-market PES schemes may be the most fair and effective means of supplying such services. Such schemes need to be administered by a collective body that have ability to collect income from all the beneficiaries to pay for the service rather than trying to commercialize the process and create a market. We must admit that ES are public goods and should focus on the challenges of providing them with funds [43]. However, sometimes, even if effective exclusive property rights cannot be established for ES, as long as the beneficiaries can obtain sufficient net income, a market-based user pay arrangement may be arranged. Using the bee pollination service mentioned above as an example, although the bees orchardist use fly to the orchard without paying for the dissemination of pollen, as long as the orchard owner gains more than he pays, he may be motivated to use bees.

Scholars who adhere to Pigouvian conceptualizations seem to assume that ES are products that are neither exclusive nor rival or at least that the degree of exclusiveness and rivalrousness is low, there is no motivation to pay for such services, and government intervention can solve the under-provisioning of ES and realize fair distribution. However, the exclusiveness of ES is not static [44]. Some non-exclusive ES could be implemented through technological progress, and some original non-rival ES are only now being exploited through competition because of congestion, in which once-abundant ES become scarce due to overuse. However, technological advances and increases scarcity do not make all ES exclusive or rivalrous. Due to technical progress and scarcity increases, property rights may be established for those ES that are regarded as pure public goods, which in turn may be transformed into quasi-public goods (club or common-pool goods) and even private goods. For example, we can build linkages between service providers and the ultimate beneficiaries through the water infrastructure, 
hydropower dams and irrigation system and then establish exclusive property rights for those ES related to water provision and regulation. Such measures help build market-based PES for such services, even if the relationship between land use and water services is unclear and undefined [45]. The existing exclusive system has established exclusive property rights for some of the previously open-access services such as capacity to absorb all kinds of pollutants. Some formerly open-access fund resources have also been property. For example, the global agreement on exclusive economic zones allows national governments to take over certain coastal fish populations, limit access to these fish populations and protect the reproduction capacity of these populations [46]. Technological advances have not only provided people with increased knowledge of ES but also have been able to continuously reduce the supply costs of ES, and some ES that was originally open access can be converted into private goods by constructing exclusive property rights. For example, Chinese companies launched the "canned-air" program, which used local forest ecological systems to provide high-quality air at the "Eco Forum Global Annual Conference Guiyang 2014", which is a typical case of the commercialization of air, which has traditionally been a public good.

However, Technological advances and scarcity increases do not cause all ES to generate exclusiveness and rivalrousness. For example, the GHG emission mitigation service provided by afforestation cannot exclude others from benefiting; when a person is benefiting from this type of ES, the ES can also be exploited by others. Indeed, for ES that are pure public goods, such as reduction of greenhouse gas emissions provided by forest ecosystems, the beneficiaries are widely distributed and cannot be clearly differentiated, and a government-financed PES may be appropriate. However, this is not necessarily an appropriate way to solve the ES supply problem given the nature of common-pool or club goods. Cooperative user payments or cooperative payments between users and governments can also be effective. Ostrom notes that communities can establish rules for using common-pool resources and develop corresponding monitoring mechanisms and that a community lifestyle conforms to these conventions [47]. The PSA program [48] implemented in 1997 in Costa Rica to protect forest ecosystems, which provide ES such as greenhouse gas mitigation, hydrological services, biodiversity conservation, and scenic beauty, alongside irrigation associations and the government, pays upstream forest owners for watershed activities to improve the base flow of the Cauca River and reduce the settlement of irrigation canals in Colombia [38]. These are classic user-government cooperation payment cases.

\subsection{Spatial and Temporal Contacts between Suppliers and Demanders}

PES of different types may have different spatial and temporal characteristics. Some ES are local public goods, and some are national and even global public goods. For example, water quality purification services yielded by watershed management are local public goods, while the climate regulation services pro- 
vided by tropical rainforests are global public goods. Some ES need only a short time to improve, while others need a long time; thus, some ES benefit the contemporary era, and some benefit future generations. When the spatial and temporal contact between users and providers is close or a direct causal relationship exists, the user-financed PES is easy to set up. Heredia in Costa Rica, for example, has established a PES program to motivate farmers to engage in protective activities by charging a water fee to water users [49]. If the spatial and temporal contacts of ES supply and demand are not similar, it is very difficult to set up a voluntary payment arrangement. For example, the beneficiaries of the climate regulation and biodiversity conservation services that tropical rain forest provides may have global impacts, but residents in the local community may be indifferent to these global services, and the willingness to pay (WTP) for people at a distance may be very small or even non-existent. Moreover, the supply of this kind of ES is difficult to improve significantly in a short period of time; that is, the point at which the benefits of ES are realized would be delayed. People usually have difficulty in predicting the future, and most people underestimate their future utility or benefit, and the weight given to future benefits is less than the current benefit. People are often only good at noticing rapid changes and responding to those but are not good at dealing with things that change slowly. This behavior is because we do not notice such changes, but we often have no measure for such changes. For example, climate change is a slow process, but few people think their behavior will directly affect climate change. Therefore, for those PES programs for which the return is delayed for long, users have lower motivations for payment, the discount rate may be higher, and people may be more likely to rely on governmental payments.

The more complex the spatial and temporal contacts between ES supply and demand are, the higher the transaction costs are [36]. If it is more difficult for private markets to play a role, appropriate government interventions become necessary to solve ES degeneration. This may be the most important reason that biodiversity conservation, efforts to improve climate stability and important watershed conservation projects are dominated by governments.

\subsection{Relationships between ES and Private Goods}

If the under-provision of ES is directly related to necessity, production input, or the quality of personal belongings, the affected users have incentives to pay voluntarily. When such payments increase economic income, users are especially willing to pay. For example, in the late 1980s, the Kanis tribe of India introduced the fruit of a particular plant (Trichopus zeylanicus travancoricus) in the western region of Ghats to the tropical botanical garden institute. The institute used the fruits and leaves of this plant to develop a new drug for a profit, and Arya Vaidya Pharmacy Ltd. (a private pharmaceutical company) signed a seven-year production and sales contract. The institute received approximately $\$ 25$ thousand in licensing fees and $2 \%$ of the drug sales royalties and split the two benefits in half with the Kanis tribe to compensate them for their intellectual input and 
sustainable forest management. The pharmaceutical company bought 5 tons of plant leaves from the Kanis tribe per month. Planting and harvesting employed $500-1000$ families in this tribe [44]. As another example, Energia Global is a private hydroelectric power company that provides electricity to 40,000 people located in the Sarapigui Valley in Costa Rica. Two tributaries of approximately 5800 hectares are the water source regions on which this company's power generation depends. To maximize electricity generation and income, power plants must run at full capacity, but the two small reservoirs provide only five hours of flow. Energia Global wants to increase river flow and reduce reservoir silting, and it is believed that increasing forest coverage in the upstream catchments can achieve both. Energia Global estimated that if the investment can increase flows to 460,000 cubic meters of water (worth approximately $\$ 30,000$ ), then, the company can make a profit. Therefore, Energia Global provides $\$ 18$ per hectare to FONAFIFO $^{10}$ (Fondo Nacional de Financiamiento Forestal, i.e. the National Forest Office and National Fund for Forest Financing), and FONAFIFO provides an additional $\$ 30$ in cash per hectare to the upstream private land stewards who agreed to engage in reforestation, sustainable forestry and forests protection [38].

For those ES that are not reflected in the quality of private goods or are not closely related to the production of private goods, such as climate stability, gas adjustment, ultraviolet radiation prevention, human interference regulation and other services, the motives for voluntarily paying to supply these services may be very low, and a government-led PES scheme is likely to be a more appropriate choice.

\subsection{Additionality}

Additionality is the difference between the number of ES with and without PES schemes [7] [10], that is, the increased number of ES provided by PES. To guarantee additionality, the number of services provided by the ecosystem in the absence of PES is needed as a baseline reference. To determine this benchmark, we should not only consider the ES level at the beginning of a PES program but also consider the influence of external factors on the ES supplier's behavior during the implementation of PES [50]. Normally, low-cost practices are based on historical benchmarks, but this approach fails to consider socio-economic changes in the use of resources [10]. There are also many PES programs that do not calculate the benchmarks but are paid only by the activities that the protocol requires [51]. Obtaining additionality may not only be a trade-off between increased management costs, negative spillover effects, and impact on equity and welfare [52] but could also result in suppliers failing to observe the agreement, especially when the supervision cost and the opportunity cost of compliance are high [53]. If the evaluation of additionality is accurate and low cost, the potential

${ }^{10} \mathrm{~A}$ semiautonomous institute established by the government of Costa Rica. It provides incentives for reforestation by compensating the land stewards for their commitment to reforestation. Most of the fund is from the $5 \%$ national oil tax [38]. 
payers, especially direct users, will be more likely to consider the implementation of a PES scheme. In contrast, if the evaluation of additionality is not accurate and is high cost, the beneficiaries will not implement a PES scheme.

The percentage of the payer's additionality is an important factor that affects the payment arrangement. When the expected additionality is possible but the use of exclusive technology cannot guarantee enough additionality, or if the exclusive cost is too high, the user will not consider a PES scheme. For PES programs that contribute significantly to the sustainable development of society but contribute little to economic growth, such as the construction of non-profit nature reserves and public welfare forests, the private sector is generally not interested in such programs, and the mechanisms cannot play a role. Without government intervention, the ES supply will be inadequate [8] [17]. In addition to market failures in the supply of public goods, the reasons for using government intervention for ES supply also include unequal distribution caused by competitive markets and the paternalistic worry that people will not act in their own best interests. The formation of sufficient resources may require involuntary means such as taxation and compulsory fees [1]. A governmental (participation) payment arrangement may be the appropriate choice to evaluate additionality for those PES programs with wide ranges of beneficiaries and high costs.

\section{Conclusions}

Defining the conditions and factors influencing PES is the fundamental basis for explaining the coexistence of various PES in the real world, predicting PES emergence and choosing the PES type. In this paper, the key to determining whether a PES is appropriate was found to be analyzing the expected net benefit. When a PES program enables beneficiaries to get a satisfactory number of ES, when the net income exceeds the opportunity cost, and when beneficiaries have the ability to bear all the costs, it can be assumed that the beneficiaries will spontaneously implement the program. When a PES is unprofitable or if beneficiaries are incapable of bearing the costs required, they must establish a form of organization to implement such a PES scheme. If the cooperative group is able to determine the number of ES and agrees to pay for the number of ES, when the total return of the expected partner exceeds the cost of supply, when the expected net return of each of the partners is greater than that of the input resources used in the PES program for alternative activities, and when they have the ability to pay for all of ES supply costs, we can assume that the cooperator-financed PES will occur. When the conditions of an individual's payment or cooperation payment cannot be met, and when the beneficiary group is large, if the government expects their net income to exceed the opportunity cost and has the ability, and as long as the government provides a number of ES that meet the needs of the beneficiaries, it can be assumed that the government will implement PES.

The cost of implementing PES generally includes ES production costs, transaction costs between payers and providers, transaction costs among payers, and 
the sunk costs caused by undesired government decisions. The benefits can be divided into two categories: payers' benefits and free riders' benefits. When the payers are users, payers' evaluations of their ES may be significantly higher than that of the free riders. When the payers are non-users, payers can give a higher evaluation of the free riders getting ES. The advantage of user-financed PES is efficiency, but the organization cost among payers, transaction costs between providers and payers, and free riders increase with the supply and demand groups. If the target of ES is not only beneficial to the public welfare but can also save production costs for special users, as long as the special users expect to get enough net income, they may have motivations to cooperate with the government to implement PES. A government-financed PES scheme does not have the organization cost among payers, and there may be lower transaction cost between payers and suppliers and fewer free riders than in a user-financed PES scheme. In the analysis of the cooperation PES between governments and users, it is necessary to examine the sunk cost if governments' mandatory decisions cause the loss of other cooperative payers.

When the net income of the PES cannot be accurately evaluated, it is necessary to examine the situational variables that affect the costs and benefits of PES. The characteristics of groups and ES, the spatial and temporal scales of suppliers and demanders, the relationship between ES and private goods, and additionality are important situational variables that the payment arrangements. With a larger group, the higher the non-exclusiveness and non-rivalrousness degree of ES will be, the less close correlation between suppliers and demanders is, and the lower the correlation with private goods will be, the more difficult to evaluate or secure access to additionality, and it is appropriate to establish a government-financed PES scheme rather than establishing a market-based PES.

\section{Acknowledgements}

The authors would like to acknowledge financial support from the Double First Class Construction Project of Hunan Agricultural University under grant No. SYL201802027.

\section{Conflicts of Interest}

The authors declare no conflicts of interest regarding the publication of this paper.

\section{References}

[1] Farley, J. and Costanza, R. (2010) Payments for Ecosystem Services: From Local to Global. Ecological Economics, 69, 2060-2068.

https://doi.org/10.1016/j.ecolecon.2010.06.010

[2] Millennium Ecosystem Assessment (2003) Ecosystems and Human Well-Being: A Framework for Assessment. Island Press, Washington DC.

[3] Millennium Ecosystem Assessment (2005) Ecosystems and Human Well-Being: Syn- 
thesis. Island Press, Washington DC.

[4] Bratman, G.N., Anderson, C.B., Berman, M.G., Cochran, B., de Vries, S., Flanders, J., Daily, G.C., et al. (2019) Nature and Mental Health: An Ecosystem Service Perspective. Science Advances, 5, eaax0903. https://doi.org/10.1126/sciadv.aax0903

[5] Jenkins, W.A., Murray, B.C., Kramer, R.A. and Faulkner, S.P. (2010) Valuing Ecosystem Services from Wetland Restoration in the Mississippi Alluvial Valley. Ecological Economics, 69, 1051-1061. https://doi.org/10.1016/j.ecolecon.2009.11.022

[6] Costanza, R., d'Arge, R., de Groot, R., Farber, S., Grasso, M., Hannon, B., Van den Belt, M., et al. (1997) The Value of the World's Ecosystem Services and Natural Capital. Nature, 387, 253-260. https://doi.org/10.1038/387253a0

[7] Wunder, S. (2005) Payments for Environmental Services: Some Nuts and Bolts. CIFOR Occasional Paper 42.

[8] Muradian, R., Corbera, E., Pascual, U., Kosoy, N. and May, P.H. (2010) Reconciling Theory and Practice: An Alternative Conceptual Framework for Understanding Payments for Environmental Services. Ecological Economics, 69, 1202-1208. https://doi.org/10.1016/j.ecolecon.2009.11.006

[9] Tacconi, L. (2012) Redefining Payments for Environmental Services. Ecological Economics, 73, 29-36. https://doi.org/10.1016/j.ecolecon.2011.09.028

[10] Engel, S. (2016) The Devil in the Detail: A Practical Guide on Designing Payments for Environmental Services. International Review of Environmental and Resource Economics, 9, 131-177. https://doi.org/10.1561/101.00000076

[11] Muradian, R., Arsel, M., Pellegrini, L., Adaman, F., Aguilar, B., Agarwal, B., Urama, K., et al. (2013) Payments for Ecosystem Services and the Fatal Attraction of Win-Win Solutions. Conservation Letters, 6, 274-279. https://doi.org/10.1111/j.1755-263X.2012.00309.x

[12] Ezzine-de-Blas, D., Wunder, S., Ruiz-Pérez, M. and Moreno-Sanchez, R.dP. (2016) Global Patterns in the Implementation of Payments for Environmental Services. PLOS ONE, 11, e0149847. https://doi.org/10.1371/journal.pone.0149847

[13] Lewison, R.L., An, L. and Chen, X. (2017) Reframing the Payments for Ecosystem Services Framework in a Coupled Human and Natural Systems Context: Strengthening the Integration between Ecological and Human Dimensions. Ecosystem Health and Sustainability, 3, Article ID: 1335931. https://doi.org/10.1080/20964129.2017.1335931

[14] Schomers, S. and Matzdorf, B. (2013) Payments for Ecosystem Services: A Review and Comparison of Developing and Industrialized Countries. Ecosystem Services, 6, 16-30. https://doi.org/10.1016/j.ecoser.2013.01.002

[15] Pagiola, S. and Platais, G. (2007) Payments for Environmental Services: From Theory to Practice. World Bank, Washington DC.

[16] Engel, S., Pagiola, S. and Wunder, S. (2008) Designing Payments for Environmental Services in Theory and Practice: An Overview of the Issue. Ecological Economics, 65, 663-674. https://doi.org/10.1016/j.ecolecon.2008.03.011

[17] Vatn, A. (2010) An Institutional Analysis of Payments for Environmental Services. Ecological Economics, 69, 1245-1252. https://doi.org/10.1016/j.ecolecon.2009.11.018

[18] Kemkes, R.J., Farley, J. and Koliba, C.J. (2010) Determining When Payments Are an Effective Policy Approach to Ecosystem Service Provision. Ecological Economics, 69, 2069-2074. https://doi.org/10.1016/j.ecolecon.2009.11.032

[19] Pattanayak, S.K., Wunder, S. and Ferraro, P.J. (2010) Show Me the Money: Do 
Payments Supply Environmental Services in Developing Countries? Review of Environmental Economics and Policy, 4, 254-274. https://doi.org/10.1093/reep/req006

[20] Grima, N., Singh, S.J., Smetschka, B. and Ringhofer, L. (2016) Payment for Ecosystem Services (PES) in Latin America: Analysing the Performance of 40 Case Studies. Ecosystem Services, 17, 24-32. https://doi.org/10.1016/j.ecoser.2015.11.010

[21] Pfaff, A., Rodriguez, L.A. and Shapiro-Garza, E. (2019) Collective Local Payments for Ecosystem Services: New Local PES between Groups, Sanctions, and Prior Watershed Trust in Mexico. Water Resources and Economics, 28, Article ID: 100136. https://doi.org/10.1016/j.wre.2019.01.002

[22] Calle, A., Montagnini, F. and Zuluaga, A.F. (2009) Farmer's Perceptions of Silvopastoral System Promotion in Quindío, Colombia. Bois et Forets des Tropiques, 300, 79-94. https://doi.org/10.19182/bft2009.300.a20417

[23] Van Hecken, G. and Bastiaensen, J. (2010) Payments for Ecosystem Services in Nicaragua: Do Market-Based Approaches Work? Development and Change, 41, 421-444. https://doi.org/10.1111/j.1467-7660.2010.01644.x

[24] Rios, A.R. and Pagiola, S. (2010) Poor Household Participation in Payments for Environmental Services in Nicaragua and Colombia. In: Tacconi, L., Mahanty, S. and Suich, H., Eds., Payments for Environmental Services, Forest Conservation and Climate Change: Livelihoods in the REDD? Edward Elgar, Northampton, 212-243.

[25] Pascual, U. and Perrings, C. (2007) Developing Incentives and Economic Mechanisms for in Situ Biodiversity Conservation in Agricultural Landscapes. Agricultural Ecosystems and Environment, 121, 256-268.

https://doi.org/10.1016/j.agee.2006.12.025

[26] Van Noordwijk, M. and Leimona, B. (2010) Principles for Fairness and Efficiency in Enhancing Environmental Services in Asia: Payments, Compensation or Co-Investment? Ecology and Society, 15, 17.

http://www.ecologyandsociety.org/vol15/iss4/art17 https://doi.org/10.5751/ES-03664-150417

[27] Wunder, S. (2015) Revisiting the Concept of Payments for Environmental Services. Ecological Economics, 117, 234-243. https://doi.org/10.1016/j.ecolecon.2014.08.016

[28] Davis, L.E. and North, D.C. (1971) Institutional Change and American Economic Growth. Cambridge University Press, Cambridge. https://doi.org/10.1017/CBO9780511561078

[29] Masten, S.E., Meehan, J.W. and Snyder, E.A. (1991) The Costs of Organization. Journal of Law, Economics, and Organization, 7, 1-25.

[30] Pagiola, S., Rios, A.R. and Arcenas, A. (2010) Poor Household Participation in Payments for Environmental Services: Lessons from the Silvopastoral Project in Quindío, Colombia. Environmental and Resource Economics, 47, 371-394. https://doi.org/10.1007/s10640-010-9383-4

[31] Adhikari, B. and Agrawal, A. (2013) Understanding the Social and Ecological Outcomes of PES Projects: A Review and an Analysis. Conservation and Society, 11, 359-374. https://doi.org/10.4103/0972-4923.125748

[32] Buchanan, J.M. (1999) The Demand and Supply of Public Goods. Liberty Fund, Incorporated, Indianapolis.

[33] Kaimowitz, D. and Angelsen, A. (2008) Will Livestock Intensification Help Save Latin America's Tropical Forests? Journal of Sustainable Forestry, 27, 6-24. https://doi.org/10.1080/10549810802225168

[34] Jayachandran, S. (2013) Liquidity Constraints and Deforestation: The Limitations of 
Payments for Ecosystem Services. American Economic Review, 103, 309-313. https://doi.org/10.1257/aer.103.3.309

[35] Mueller, D.C. (2003) Public Choice III. Cambridge University Press, Cambridge.

[36] North, D.C. (1990) Institutions, Institutional Change and Economic Performance. Cambridge University Press, Cambridge. https://doi.org/10.1017/CBO9780511808678

[37] Ostrom, E. (1990) Governing the Commons: The Evolution of Institutions for Collective Action. Cambridge University Press, New York. https://doi.org/10.1017/CBO9780511807763

[38] Perrot-Maître, D. and Davis, P. (2001) Case Studies: Developing Markets for Water Services from Forests. Forest Trends, Washington DC.

[39] Corbera, E., Kosoy, N. and Tuna, M.M. (2007) Equity Implications of Marketing Ecosystem Services in Protected Areas and Rural Communities: Case Studies from Meso-America. Global Environmental Change, 17, 365-380. https://doi.org/10.1016/j.gloenvcha.2006.12.005

[40] Coase, R. (1988) The Firm, the Market and the Law. University of Chicago Press, Chicago

[41] Bowles, S. and Gintis, H. (2011) A Cooperative Species: Human Reciprocity and Its Evolution. Princeton University Press, Princeton. https://doi.org/10.23943/princeton/9780691151250.001.0001

[42] Wan, B.T., Zou, S.M., Li, Y. and Wang, J.N. (2008) Payment for Ecosystem Services in Practice: Cases Analysis and Exploration. China Environmental Science Press, Beijing.

[43] Kaul, I., Goulven, K.L. and Schnupf, M. (2002) Financing Global Public Goods: New Tools for New Challenges. A Policy Dialogue. United Nations Development Program, New York.

[44] Landell-Mills, N. and Porras, I. (2002) Silver Bullet or Fool's Gold? A Global Review of Markets for Forest Environmental Services and Their Impact on the Poor. International Institute for Environment and Development (IIED), London.

[45] Bruijnzeel, L.A. (2004) Hydrological Functions of Tropical Forests: Not Seeing the Soil for the Trees? Agriculture, Ecosystems and Environment, 104, 185-228. https://doi.org/10.1016/j.agee.2004.01.015

[46] Bromley, D.W. (2005) Purging the Frontier from Our Mind: Crafting a New Fisheries Policy. Reviews in Fish Biology and Fisheries, 15, 217-229.

https://doi.org/10.1007/s11160-005-4866-Z

[47] Ostrom, E., Gardner, R. and Walker, J. (1994) Rules, Games and Common-Pool Resources. University of Michigan Press, Ann Arbor. https://doi.org/10.3998/mpub.9739

[48] Pagiola, S. (2008) Payment for Environmental Services in Costa Rica. Ecological Economics, 65, 712-724. https://doi.org/10.1016/j.ecolecon.2007.07.033

[49] Castro, E. (2001) Costarrican Experience in the Charge for Hydro Environmental Services of the Biodiversity to Finance Conservation and Recuperation of Hillside Ecosystems. The International Workshop on Market Creation for Biodiversity Products and Services, OECD, Paris, 25-26 January 2001.

[50] Naeem S., Ingram, J.C., Varga, A., Agardy, T., Barten, P., Bennett, G., Wunder, S., et al. (2015) Get the Science Right When Paying for Nature's Services: Few Projects Adequately Address Design and Evaluation. Science, 347, 1206-1207.

https://doi.org/10.1126/science.aaa1403 
[51] Wunder, S., Engel, S. and Pagiola, S. (2008) Taking Stock: A Comparative Analysis of Payments for Environmental Services Programs in Developed and Developing Countries. Ecological Economics, 65, 834-852.

https://doi.org/10.1016/j.ecolecon.2008.03.010

[52] Börner, J., Baylis, K., Corbera, E., Ezzine-de-Blas, D., Honey-Rosés, J., Persson, U.M. and Wunder, S. (2017) The Effectiveness of Payments for Environmental Services. World Development, 96, 359-374. https://doi.org/10.1016/j.worlddev.2017.03.020

[53] Hanley, N. and White, B. (2013) Incentivizing the Provision of Ecosystem Services. International Review of Environmental and Resource Economics, 7, 299-331. https://doi.org/10.1561/101.00000064 